\title{
STUDYING THE EFFECT OF GEOMETRICAL NAIL LAYOUT ON THE PERFORMANCE OF SOIL-NAILED WALLS: PHYSICAL AND NUMERICAL MODELING
}

\author{
Mohsen SABERMAHANI * and Hamed NURI
}

School of Civil Engineering, Iran Univ. of Science and Technology, 1684613114 Tehran, Iran

*Corresponding author's e-mail: msabermahani@iust.ac.ir

\begin{tabular}{|c|c|}
\hline ARTICLE INFO & ABSTRACT \\
\hline Article history: & \multirow{10}{*}{$\begin{array}{l}\text { Soil nailing is a reliable method of stabilising earth and rock slopes, but the geometrical layout of } \\
\text { soil nails has not been well studied. The current research examined the effect of the geometrical } \\
\text { layout of soil nails using analytical and physical modelling. The results of limit equilibrium } \\
\text { analysis for different nail layouts are presented. The target gravity level was } 50 \mathrm{~g} \text { for centrifuge } \\
\text { models and all models had a safety factor of } 1.35 \text { at this level. The parameters studied were base } \\
\text { nail length, angle of nail tail extension, horizontal spacing of nails, and nail density. The limit } \\
\text { equilibrium results showed that, when longer nails were used, the nail density could be decreased. } \\
\text { The results of centrifuge modelling confirmed that different layouts at a similar safety factor did } \\
\text { not show similar levels of displacement. Also, nail density was the most influential parameter } \\
\text { affecting soil-nailed wall performance. An empirical relationship was observed between } \\
\text { displacements of the wall crest and nail density. An interesting similarity was observed between } \\
\text { the predicted slip surface and the slip surface that formed during physical modelling. }\end{array}$} \\
\hline Received 19 September 2020 & \\
\hline Accepted 19 January 2021 & \\
\hline Available online 11 February 2021 & \\
\hline Keywords: & \\
\hline Sands & \\
\hline Soil nailing & \\
\hline Slope stabilization & \\
\hline Centrifuge modeling & \\
\hline & \\
\hline
\end{tabular}

\section{LIST OF SYMBOLS}

\begin{tabular}{|c|c|}
\hline$C$ & is the cohesion \\
\hline$C_{c}$ & is the coefficient of curvature \\
\hline$C_{u}$ & is the coefficient of uniformity \\
\hline$D_{n}$ & is the nail density \\
\hline$D_{r}$ & is the relative density of sand \\
\hline$D_{50}$ & is the average grain size \\
\hline$E$ & is the modulus of elasticity \\
\hline$e_{\max }$ & is the maximum void ratio \\
\hline$e_{\min }$ & is the minimum void ratio \\
\hline$F S$ & is the safety factor \\
\hline$F S_{50 g}$ & $\begin{array}{l}\text { is the safety factor of the equivalent analytical } \\
\text { model at } 50 \mathrm{~g} \text { centrifugal gravity }\end{array}$ \\
\hline$F S_{60 g}$ & $\begin{array}{l}\text { is the safety factor of the equivalent analytical } \\
\text { model at } 60 \mathrm{~g} \text { centrifugal gravity }\end{array}$ \\
\hline$F S_{70 g}$ & $\begin{array}{l}\text { is the safety factor of the equivalent analytical } \\
\text { model at } 70 \text { g centrifugal gravity }\end{array}$ \\
\hline$G_{S}$ & is the specific gravity of solid particles \\
\hline$H$ & is the wall height \\
\hline$L$ & is the base nail length \\
\hline$N$ & is the centrifugal acceleration, scaling factor \\
\hline$n$ & is the number of rows of nail \\
\hline$S_{H}$ & is the horizontal spacing of nails \\
\hline$T$ & is the tensile capacity \\
\hline$U(t)$ & is the crest total displacement \\
\hline$U(x)$ & is the crest horizontal displacement \\
\hline$U(y)$ & is the crest vertical displacement \\
\hline$\sum L_{i}$ & is the summation of nail lengths \\
\hline$\alpha$ & is the angle of nail tail extension \\
\hline$\varphi$ & is the angle of internal friction \\
\hline$\Theta$ & is the inclination of the nails with horizontal \\
\hline
\end{tabular}

\section{INTRODUCTION}

Soil nailing is an in-situ reinforcing method for soil that was developed in the early 1960s using tunnel bolts and multi-anchor systems (Burland et al., 2012). A soil nailing system consists of soil nails, wall facing, and nail-head plates that connect the nail to the facing. The soil is reinforced by inserting steel bars into the soil at suitable distances as the excavation proceeds. The FHWA-NHI 14007 lists the advantages of this method such as stabilisation of the soil due to staged construction, feasibility in different topographical conditions and cost-effectiveness, etc. (Lazarte et al., 2015). Because the use of soil nailing and the development of different schemes for the stabilisation of the excavations has increased, it is difficult to determine one design that satisfies the technical needs of a project while keeping the costs to a minimum. As a result, it is necessary to understand the behavior of the stabilised wall and the parameters affecting the stabilisation and deformation of the wall.

The first step in the design of a soil-nailed wall is to conduct limit equilibrium analysis or another type of slope stability analysis on the proposed design layout (Burland et al., 2012) to evaluate the equilibrium of the internal and external forces acting on the wall. After assuming a specific factor of safety (FS) as specified by the design codes, it is evident that plenty of design layouts could possibly satisfy the specified FS. Three categories of parameters could affect the performance of a soil-nailed wall. The first category pertains to the geometry of a single nail and 
includes nail length, angle, diameter and the horizontal and vertical distances between nails. The second category relates to the wall facing and includes its mechanical properties and nail-head properties. The third category, which is less studied, is the general layout of the nails.

The parameters defining a regular layout of nails were introduced by Ghalehnovi (2014). Although most studies evaluated the first and second categories (Milligan and Tei, 1998; Rotte and Viswanadham, 2012; Zhang et al., 2014; Shahraki Ghadimi et al., 2017), Ghalehnovi (2014) concluded that the third category also had a considerable effect on the performance of a soil-nailed wall.

Milligan and Tei (1998) performed geotechnical centrifuge experiments on 24 models of vertically nailed walls that were $20 \mathrm{~cm}$ in height, prepared by dry Leighton-Bazard sand. Plastic bags filled with fluid were used to sustain the lateral pressure on the wall before excavation simulation. They reported that, in all cases, failure was caused by nail pullout rather than nail breakage.

Tufenkjian and Vucetic (2000) evaluated the behavior of a soil-nailed wall under earthquake excitation using a geotechnical centrifuge. They reported that longer nails resulted in better performance of the nailed wall. Zhang et al. (2001) performed centrifuge tests on soil-nailed wall models using fine-grained material. They observed that short nails caused external instability in the wall and longer nails produced internal instability. They concluded that increasing the nail length with respect to wall height $\left(L_{n} / H\right)$ improved performance of the wall in terms of displacement and stability.

Askarinejad (2006) investigated the effect of nail stiffness and roughness as well as facing stiffness on the deformation of a soil-nailed wall using a geotechnical centrifuge. The results showed that an increase in nail stiffness and roughness as well as facing stiffness reduced the deformation of the wall. Wang et al. (2010) studied the effect of soil nailing on the seismic response of a soil-nailed wall through centrifuge modelling. They reported that the nails decreased wall displacement. They also concluded that the nail layout did not affect the wall performance when the nails of sufficient length were used.

Zhang et al. (2013) investigated the failure and deformation of a soil-nailed wall under vertical surface loading using centrifuge modelling. They investigated the effect of nail length and backslope angle of the wall on the deformation and stability of the wall. It was observed that nail deformation differed in the upper and lower halves of the wall and that the ultimate load-bearing of the slope decreased significantly as the slope gradient increased and nail length decreased.

Sabermahani et al. (2018) used centrifuge modelling to investigate the effect of nail density and surcharge magnitude on the deformation of a soil- nailed wall. The results indicated that surcharge magnitude and its distance from the wall crest strongly influenced wall performance. As the centrifugal acceleration increased in accordance with the scaling laws and therefore, nail density decreased, deformation increased and the FS of the slope decreased. Shahnazari et al. (2019) performed centrifuge tests on three-dimensional convex trenches stabilised by soil nailing. They reported that the quality of the connection between trenches played an important role in the stability of the nailed trench.

Nail density $D_{n}$ is the mean nail length required to stabilise a unit area of the excavation wall. For regular nail layouts with a wall height of $H, n$ rows of nails with length of each row as $L_{i}$ and horizontal spacing of nails as $S_{h}, D_{n}$ can be calculated as:

$D_{n}=\frac{\sum_{i=1}^{n} L_{i}}{S_{H} \times H}$

Ghalehnovi (2014) defined the linear layout for nails shown in Figure 1 and introduced the variables of base nail length (L), the length of the lowest row of nails, and the angle of nail tail extension $(\alpha)$, which is the angle of the line extending along the nail ends. Ghalehnovi investigated the effect of nail layout on the FS of the wall to find the optimum design using these variables. (Sabermahani and Gholaminia, 2017) evaluated the optimum nail layout using these parameters and also considered the recommended FS and allowable deformation of the wall.

Because these studies used numerical modelling, it is necessary to verify their results using data obtained from a case study or through physical modelling tests. The current study used physical modelling under $\mathrm{Ng}$ conditions using a geotechnical centrifuge to evaluate the effect of nail layout on the deformation behavior and performance of soil-nailed walls to introduce the most important factor affecting wall performance. The parameters used to define the layout of the nails were base nail length $(L)$, angle of nail tail extension $(\alpha)$, horizontal spacing of nails $\left(S_{h}\right)$ and nail density $\left(D_{n}\right)$. In order to better compare the results, the vertical spacing of the nails $\left(S_{v}\right)$, wall height $(H)$ and angle of inclination of nails with horizontal $(\theta)$ were held constant for all models and different layouts were created by changing the values of $L, \alpha, S_{h}$ and $D_{n}$. It is worth noting that $\sum_{i=1}^{n} L_{i}$ represents the total nail length of the wall and should not be mistaken with the studied parameter $(L)$ that is the base nail length (shown in Figure 1. In fact, one can assume that $(L)$ and $(\alpha)$ are simultaneously present in the equation 1 through $\sum_{i=1}^{n} L_{i}$.

\section{LIMIT EQUILIBRIUM ANALYSIS}

Two criteria should be satisfied during the design of a soil-nailed wall. The first is the stability of the wall, which is evaluated using the factor of safety. The second is the performance of the wall, evaluated in terms of displacement. The first criterion was evaluated for different layouts using limit equilibrium analysis. 


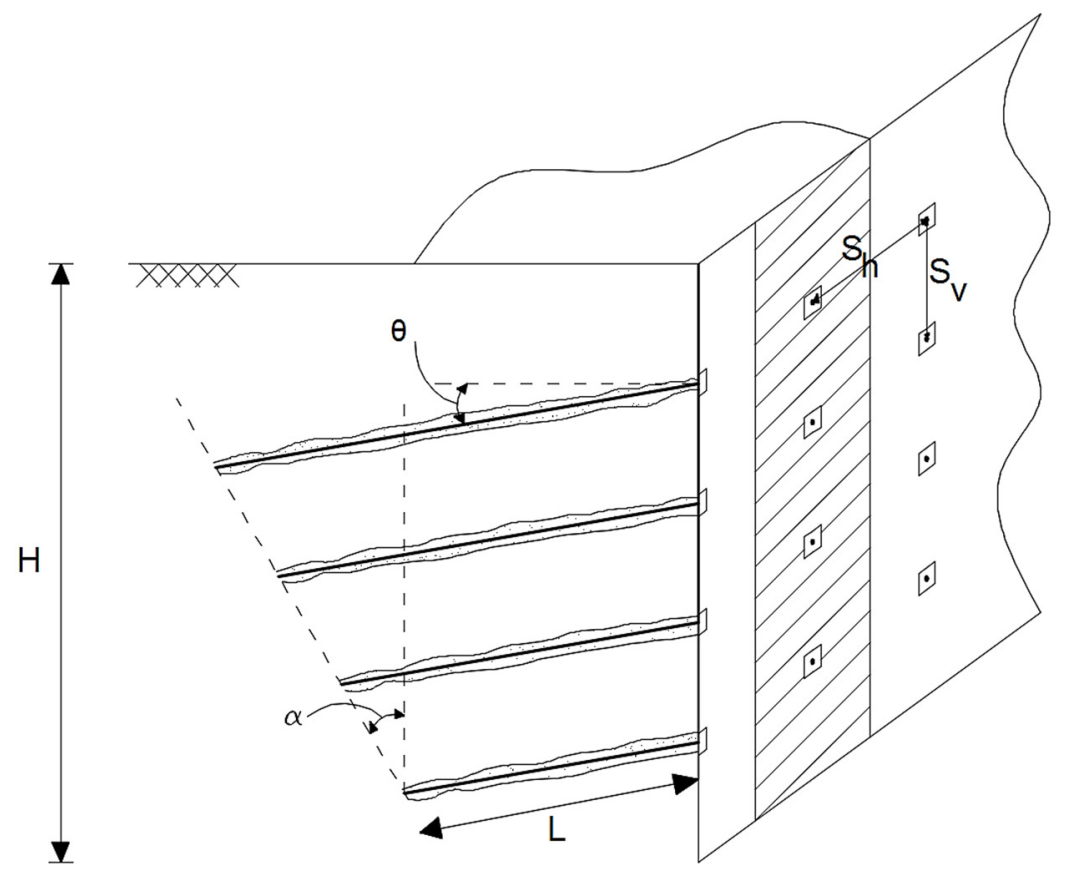

Fig. 1 Nailing layout variables $L$ and $a$ (Ghalehnovi, 2014).

Table 1 Input parameters used to define \#161 Firoozkooh sand.

\begin{tabular}{ccc}
\hline Cohesion $(\mathrm{kPa})$ & Angle of internal friction (degree) & Unit weight $\left(\mathrm{kN} / \mathrm{m}^{3}\right)$ \\
\hline 15.7 & 35 & 0.05 \\
\hline
\end{tabular}

Table 2 Input parameters used to define mechanical properties of nails in limit equilibrium analyses.

\begin{tabular}{ccccc}
\hline $\begin{array}{c}\text { Bar size } \\
(\mathrm{mm})\end{array}$ & $\begin{array}{c}\text { Material strength } \\
(\mathrm{MPa})\end{array}$ & $\begin{array}{c}\text { Bond skin friction } \\
(\mathrm{kPa})\end{array}$ & $\begin{array}{c}\text { Bond diameter } \\
(\mathrm{m})\end{array}$ & Bond safety factor* \\
\hline 30 & 400 & 200 & 0.1 & 1.5 \\
\hline
\end{tabular}

* Based on the recommendation of FHWA-SA-96-069R (Byrne et al., 1998)

The standards for the design of the soil-nailed trenches and walls include the ICE Manual of Geotechnical Engineering (Burland et al., 2012), Hong Kong GeoGuide 7 (GEO 2008) and the US Federal Highway Administration (FHWA) NHI-14007 (Lazarte et al., 2015). FHWA-SA-96-069R (Byrne et al., 1998) is a commonly used and comprehensive standard; thus, the factor of safety for the stability of the wall in the current study was based on its recommendations. According to this standard, the recommended FS for temporary and permanent excavations is 1.35 and 1.50 , respectively.

In order to evaluate the effect of nail layout on the performance of a soil-nailed wall, various layouts were created and analyzed by changing the parameters that defined the layout. In any layout with specific values of $L$ and $\alpha$, the lengths of the nails in every row are known. Assigning different values to $S_{h}$ will result in different FS values. When the value of $S_{h}$ is decreased, $D_{n}$ will increase, which will contribute to an increase in FS. For a specific layout with known values of $L$ and $\alpha$, many models can be proposed that differ only in the value of $S_{h}$ which will result in different values for $D_{n}$ and FS. However, only the
$S_{h}$ that produce values of FS $>1.35$ will be acceptable, and $S_{h}$ that results in FS $=1.35$ will be the $S_{h}$ for that specific layout.

GeoSlope software was used to analyze the stability of all layouts considered for a soil-nailed wall. The height of the model wall was $6.5 \mathrm{~m}$ in prototype dimensions to allow for the creation of physical models at 1:50 scale in the geotechnical centrifuge.

\section{MODEL DEFINITION AND INPUT PARAMETERS}

The parameters used to define the soil and nail materials in the GeoSlope model are summarized in Tables 1 and 2, respectively. Because the limit equilibrium analysis aimed to obtain the horizontal spacing of nails $S_{h}$ that yields the recommended FS of 1.35 at $50 \mathrm{~g}$ for each layout, the value of $S_{h}$ for each layout was found by trial and error until the recommended FS value of 1.35 was obtained.

The slip surface was located in GeoSlope using the "auto locate" and "grid and radius" methods. The Morgenstern-Price method was employed to calculate FS. None of the soil-nailed walls experienced surcharge loading. Figure 2 shows a conventional GeoSlope model at $L=3.5 \mathrm{~m}$ and $\alpha=20^{\circ}$. As stated, 


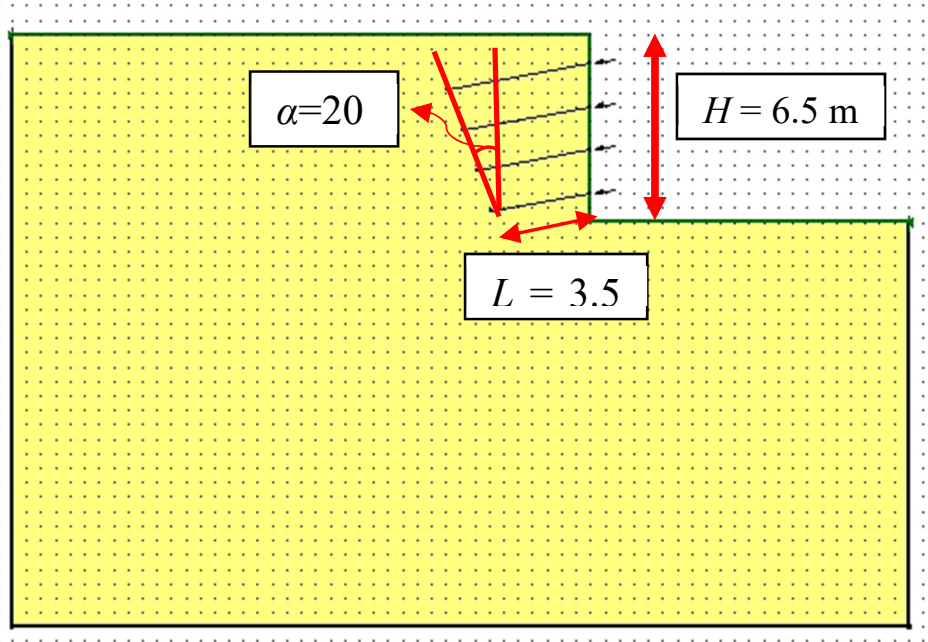

Fig. 2 Conventional limit equilibrium model.

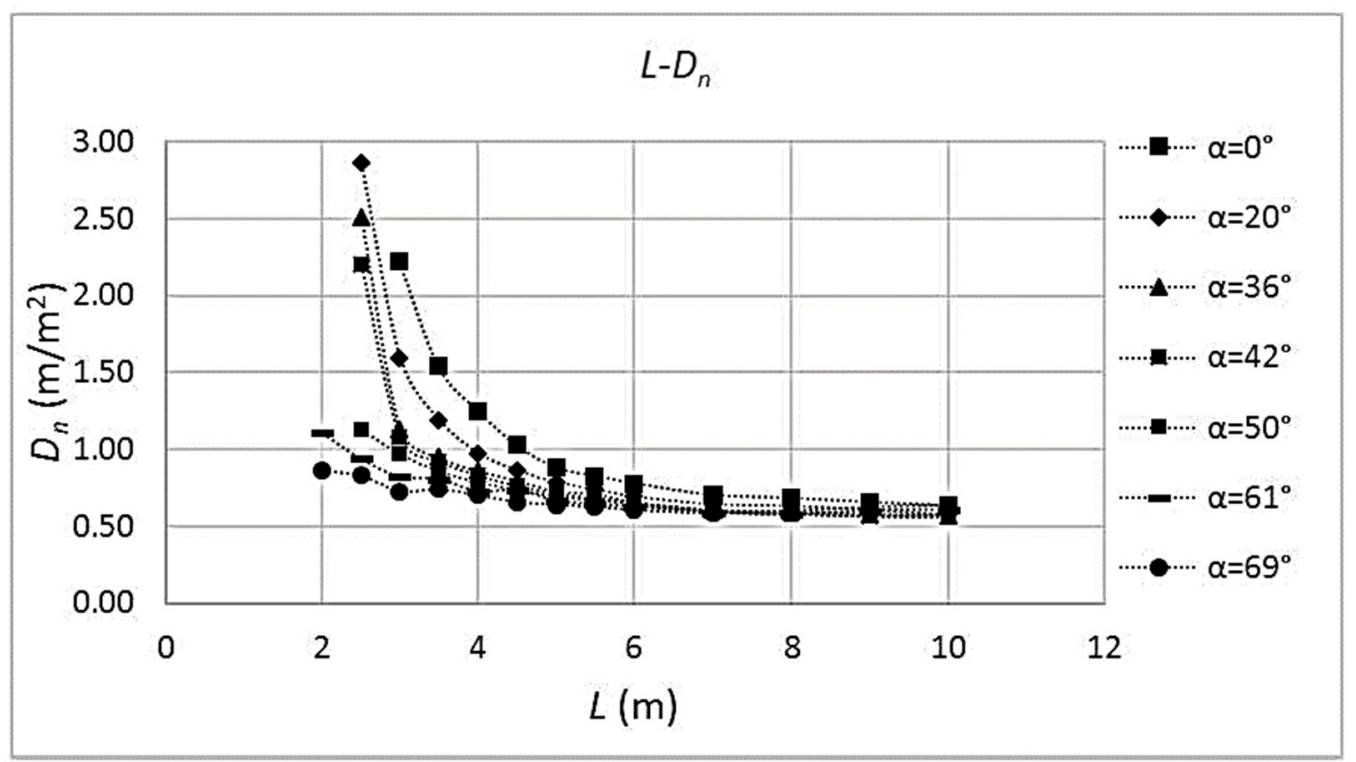

Fig. 3 Base nail length $L$ vs. nail density $D_{n}$ for different values of $\alpha(\mathrm{FS}=1.35)$.

the wall height was based on the restrictions of centrifuge modelling.

\section{LIMIT EQUILIBRIUM ANALYSIS RESULTS}

In this study, $L, \alpha$ and $S_{h}$ were varied to create different layouts with different nail densities. In order to evaluate a wide range of possible layouts to stabilise the excavation, the range selected for $L$ was $10 \mathrm{~m} \geq L \geq 2 \mathrm{~m}$ and for $\alpha$ was $69^{\circ} \geq \alpha \geq 0^{\circ}$. Again, the results were for analysis at $50 \mathrm{~g}$ and $\mathrm{FS}=1.35$. The results of limit equilibrium analysis are presented in Figures 3, 4 and 5.

Figure 3 shows that an increase in $L$ required a decrease in $D_{n}$ in order to maintain FS = 1.35; however, as $L$ increased further, a decrease in $D_{n}$ was no longer necessary to maintain FS $=1.35$. It can be seen that a decrease in $L$ required an increase in $D_{n}$ to maintain the recommended safety factor, but a further decrease in $L$ required an increase in $D_{n}$ that was no longer practical. In other words, the value of FS $=1.35$ could not be obtained with very short nails, regardless of nail density.

This behavior has been reported by Zhang et al. (2001), who stated that the use of short nails caused external instability in the soil-nailed wall. As $L$ increased, $D_{n}$ became asymptotic to a constant value, which implies that the use of longer nails requires greater horizontal spacing between nails. As $S_{h}$ increases, the full capacity of the nails is mobilized; thus, an increase in $L$ will not produce a smaller value for $D_{n}$. This is in general agreement with findings of Morgan (2002), who reported that a lower value of $D_{n}$ will lead to full mobilization of nail capacity, but the use of short nails will increase $D_{n}$, which will not be efficient.

Figure 3 shows that an increase in $\alpha$ caused a decrease in $D_{n}$. A similar trend can be seen in Figure 4. That is, at a constant value of $L$, an increase 


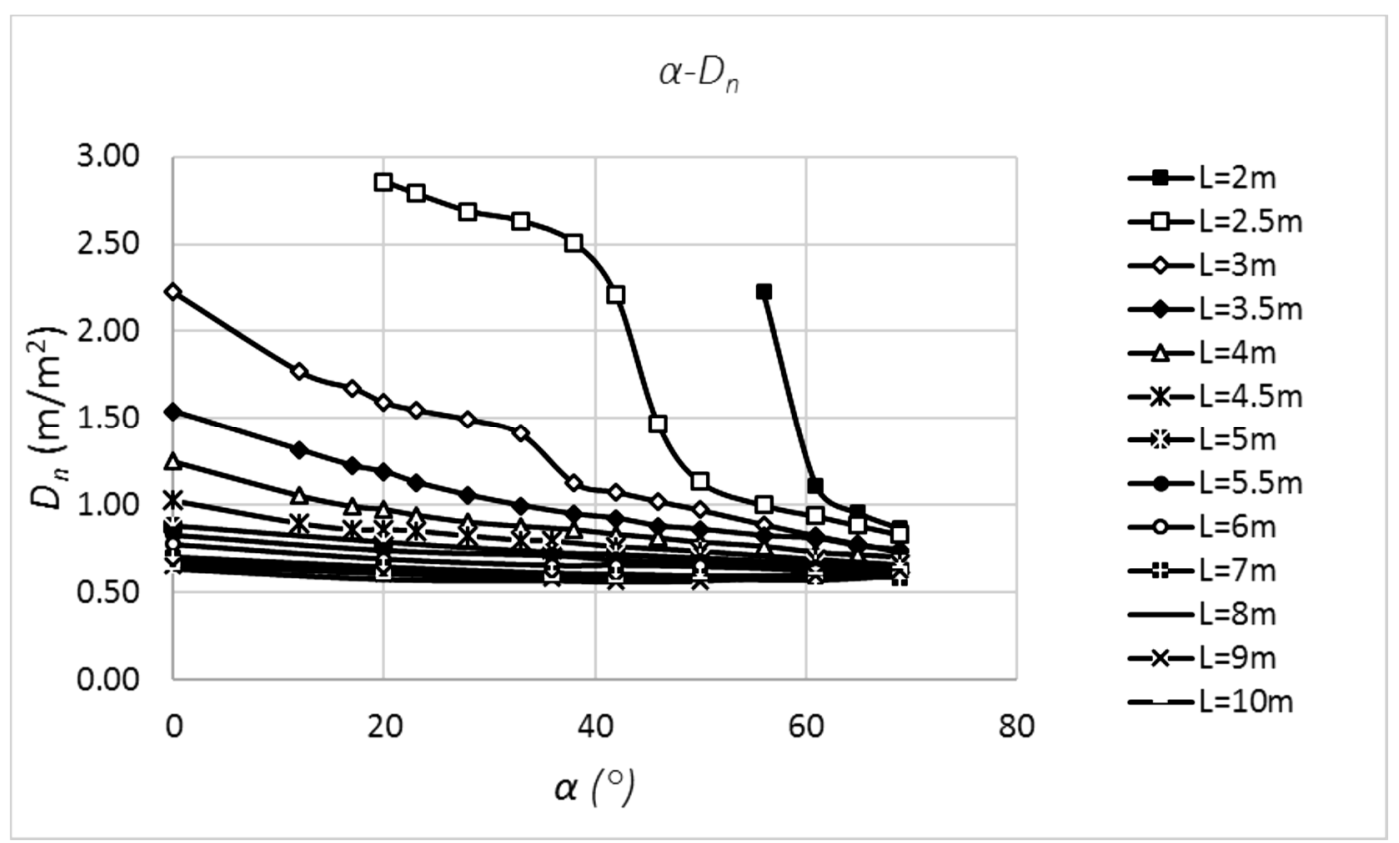

Fig. 4 The angle of nail tail extension $\alpha$ vs. nail density $D_{n}$ for different values of $L(\mathrm{FS}=1.35)$.

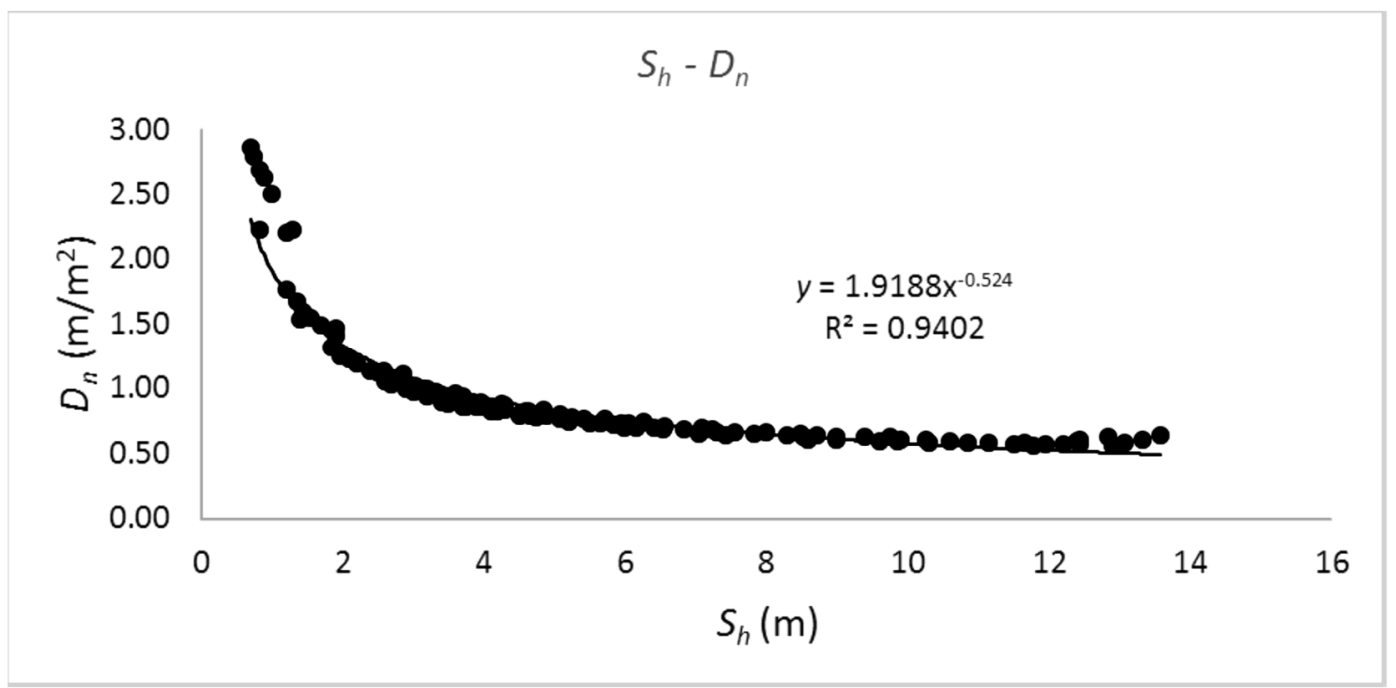

Fig. 5 Horizontal spacing of nails $S_{h}$ vs. nail density $D_{n}(\mathrm{FS}=1.35)$.

in $\alpha$ caused $D_{n}$ to decrease. Also, at a constant value of $\alpha$, an increase in $L$ caused a decrease in $D_{n}$.

The relationship between $S_{h}$ and $D_{n}$ is shown in Figure 5. As seen, an increase in $S_{h}$ caused a decrease in $D_{n}$. A further increase in $S_{h}$ did not cause a decrease in $D_{n}$, meaning that the nails had mobilized their full capacity and that either $L$ or $\alpha$ or both should increase in order to maintain FS $=1.35$. This is in agreement with the conclusions made earlier and confirms that increasing $S_{h}$ will increase the efficiency of the nails.

Seven out of 121 layouts analyzed for stabilisation of a $6.5 \mathrm{~m}$ wall were investigated using centrifuge modelling. The aim was to compare the performance of the layouts and determine the parameter that most affected the performance of the wall. The results are presented in the next section.

\section{PHYSICAL MODELLING}

Despite impressive advances and improvements in numerical modelling of geotechnical problems, physical modelling is still useful for studying geotechnical phenomena because prototype structures can be modelled at a much lower cost. Centrifuge modelling is a popular method of modelling because the effective stress can be accurately reproduced. Thus, centrifuge modelling was employed in the current study to create soil-nailed wall models with similar mechanical behavior to the prototype. It is noted that numerical modeling of the geometry to provide insight into the deformations of the wall and subsoil would have been useful. However, this was beyond the scope of this work and it is recommended for further investigation of the effects of the evaluated 


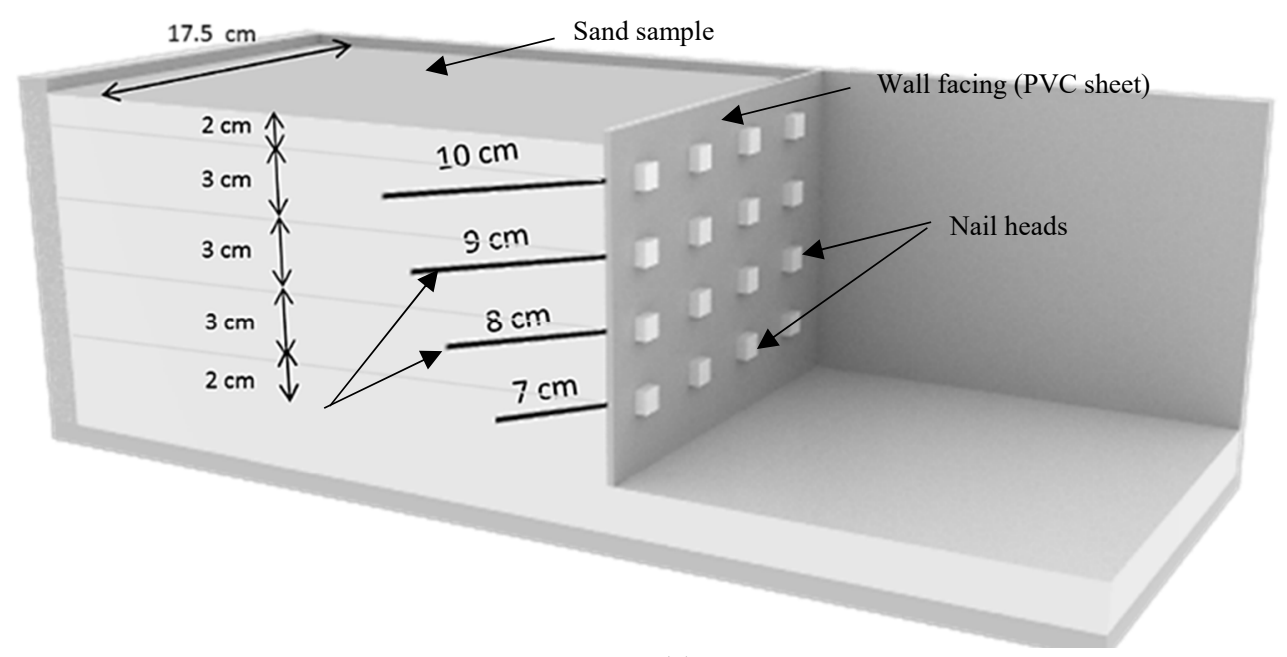

(a)

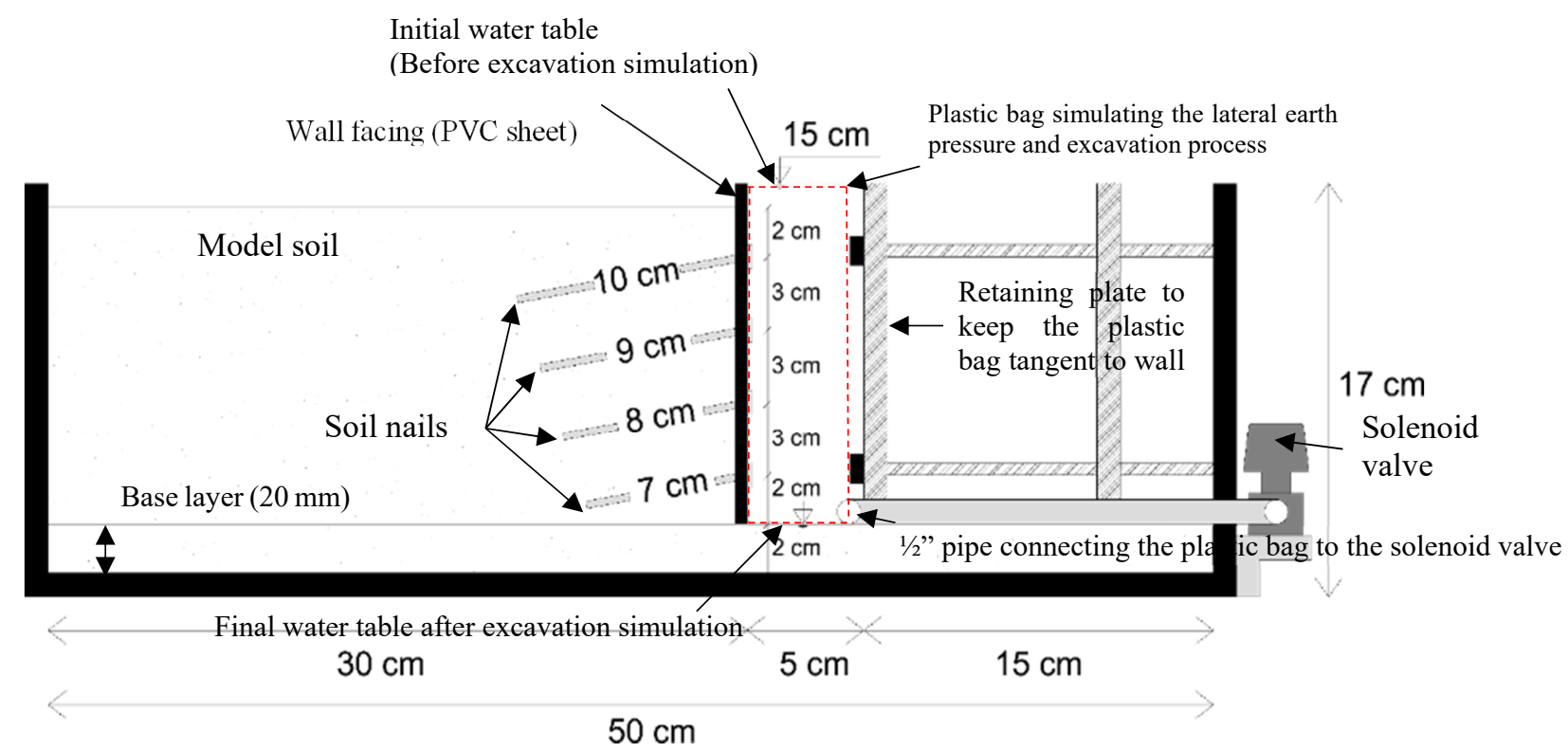

(b)

Fig. 6 Schematic of T2-7-20-4.4 model: (a) 3D view; (b) cross-section.

parameters. All layouts studied had the FHWA recommended stability FS of 1.35 (Byrne et al., 1998). The layouts that were physically modelled were selected based on the limitations of the centrifuge strongbox.

\section{TEST EQUIPMENT}

The tests were conducted at a 14-ton. $g$ centrifuge facility which is capable of reaching $200 \mathrm{~g}$ of acceleration. A strong box having internal dimensions of $500 \times 175 \times 170 \mathrm{~mm}$ (length, width, height) was used as the model container. One side of the model container was transparent Plexiglass that enabled the movements of the wall to be captured during the test. The deformations were measured by particle image velocimetry (PIV) coupled with close- range photogrammetry as described by White et al. (2003). Still images of each model were extracted from a video of the test. A plastic bag was used to simulate the lateral earth pressure before excavation as well as the excavation process in front of the wall.

\section{TEST PROCEDURE}

Figure 6 presents a 3D schematic view and a cross-section of one of the tested models. All model facings were vertical and had a height of $130 \mathrm{~mm}$. A sand layer of $20 \mathrm{~mm}$ in thickness was laid beneath the model soil to simulate the foundation soil. All layouts were modelled according to the scaling laws described by Kutter (1992) and summarized in Table 3. 
Table 3 Scaling laws in $\mathrm{Ng}$ modelling.

\begin{tabular}{lccc}
\hline Parameter & Unit & Prototype & Ng model \\
\hline Cohesion $(C)$ & $\mathrm{kN} / \mathrm{m}^{2}$ & 1 & 1 \\
Internal friction angle $(\varphi)$ & degrees & 1 & 1 \\
Length & $\mathrm{m}$ & $\mathrm{N}$ & 1 \\
Area & $\mathrm{m}^{2}$ & $\mathrm{~N}^{2}$ & 1 \\
Displacement & $\mathrm{m}$ & $\mathrm{N}$ & 1 \\
Strain & $\%$ & 1 & 1 \\
Unit weight & $\mathrm{kN} / \mathrm{m}^{3}$ & $1 / \mathrm{N}$ & 1 \\
Stress & $\mathrm{kN} / \mathrm{m}^{2}$ & 1 & 1 \\
Axial stiffness & $\mathrm{kN} / \mathrm{m}^{2}$ & $\mathrm{~N}$ & 1 \\
Flexural stiffness & $\mathrm{kN} \cdot \mathrm{m}^{2}$ & $\mathrm{~N}^{4}$ & 1 \\
Force & $\mathrm{kN}$ & $\mathrm{N}^{2}$ & 1 \\
Soil nail angle & degrees & & 1 \\
\hline
\end{tabular}

Table 4 Specifications of models and safety factors at different g-levels.

\begin{tabular}{lccccccc}
\hline Model name & $\begin{array}{c}\text { Base nail } \\
\text { length } \\
L\end{array}$ & $\begin{array}{c}\text { Angle of nail } \\
\text { tail extension } \\
(\mathrm{cm})\end{array}$ & $\begin{array}{c}\text { Horizontal } \\
\text { spacing of nails }\end{array}$ & $\begin{array}{c}\text { Nail } \\
S_{h}\end{array}$ & $\begin{array}{c}\mathrm{FS}_{50 \mathrm{~g}} * \mathrm{FS}_{60 \mathrm{~g}} \text { at } 50 \mathrm{~g} \\
\left(\mathrm{~m} / \mathrm{m}^{2}\right)\end{array}$ & $\mathrm{FS}_{70 \mathrm{~g}}$ \\
\hline T1-7-12-3.7 & 7 & 12 & 3.7 & 1.31 & 1.35 & 1.07 & 0.94 \\
T2-7-20-4.4 & 7 & 20 & 4.4 & 1.19 & 1.35 & 1.07 & 0.93 \\
T3-7-36-6.3 & 7 & 36 & 6.3 & 0.97 & 1.35 & 1.06 & 0.89 \\
T4-9-0-5.4 & 9 & 0 & 5.4 & 1.03 & 1.35 & 1.08 & 0.89 \\
T5-9-20-7.5 & 9 & 20 & 7.5 & 0.86 & 1.35 & 0.98 & 0.85 \\
T6-9-36-9.3 & 9 & 36 & 9.3 & 0.79 & 1.35 & 1.02 & 0.84 \\
T7-11-0-8.2 & 11 & 0 & 8.2 & 0.83 & 1.35 & 1.05 & 0.87 \\
T8-9-20-7.5 & 9 & 20 & 7.5 & 0.86 & 1.35 & 0.98 & 0.85 \\
\hline
\end{tabular}

* $\mathrm{FS}_{50 \mathrm{~g}}$ is the safety factor of the analytical model obtained using the GeoSlope software. Analytical model was constructed by scaling the physical model dimensions by a factor of 50 , corresponding to a prototype at $50 \mathrm{~g}$ centrifugal acceleration. The same applies to $\mathrm{FS}_{60} \mathrm{~g}$ and $\mathrm{FS}_{70} \mathrm{~g}$ with centrifugal acceleration of $60 \mathrm{~g}$ and $70 \mathrm{~g}$, respectively.

Table 5 Mechanical and physical properties of \#161 Firoozkooh sand.

\begin{tabular}{ccccccccc}
\hline $\begin{array}{c}\text { USCS } \\
\text { grade }\end{array}$ & $C_{c}$ & $C_{u}$ & $\begin{array}{c}D_{50} \\
(\mathrm{~mm})\end{array}$ & $e_{\min }$ & $e_{\max }$ & $G_{s}$ & $\begin{array}{c}C \\
(\mathrm{kPa})\end{array}$ & $\varphi$ \\
\hline $\mathrm{SP}$ & 0.88 & 1.87 & 0.25 & 0.55 & 0.87 & 2.658 & 0 & 35 \\
\hline
\end{tabular}

Although the target acceleration was $50 \mathrm{~g}$ in the present study, the centrifugal acceleration was increased up to $70 \mathrm{~g}$ in order to investigate the behavior of the wall at failure. Thus, the factors of safety (FS) of the physical models at higher accelerations were calculated and have been presented in Table 4. The calculation of FS for physical models was performed according to the scaling laws and the applied g-level for the physical model dimensions, using analytical modeling by GeoSlope software. The models have been denoted as: (test number) - $(L)-(\alpha)-\left(S_{h}\right)$. It should be noted that T8-9-20-7.5 test was conducted to evaluate the repeatability of test T5-9-20-7.5. The deformations observed in T5-7-20-4.4 and T12- 7- 20- 4.4 confirmed the repeatability of the tests with acceptable precision.

\section{MODEL MATERIALS}

MODEL SOIL

The model soil used in the tests was \#161 Firoozkooh sand, which has been tested and studied by researchers such as Sabermahani et al. (2018); thus, its strength and physical properties are known. The properties of the soil are given in Table 5 .

\section{MODEL FACING}

In order to simulate the shotcrete facing of the wall, a transparent PVC sheet of $0.6 \mathrm{~mm}$ in thickness with a tensile capacity of $T=52 \mathrm{MPa}$ and modulus of elasticity of $E=2.56 \mathrm{GPa}$ was used as described by Sabermahani et al. (2018). The model facing was $175 \mathrm{~mm}$ in width and $130 \mathrm{~mm}$ in height, which corresponded to the wall dimensions. A slim strip of 

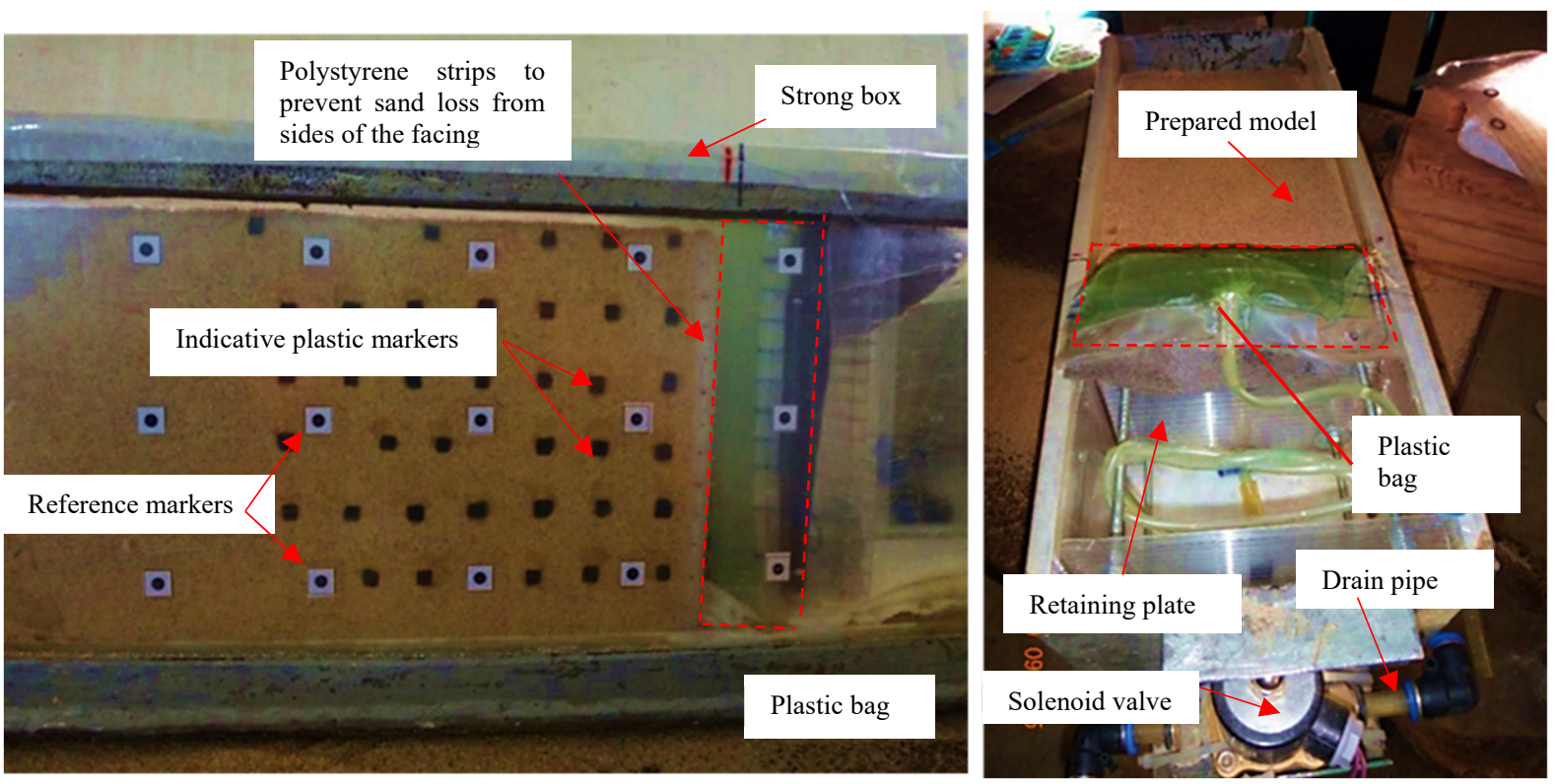

Fig. 7 T3-7-36-6.3 model and equipment used.

polystyrene was used as a filler to prevent the loss of sand at the sides of the PVC facing. These strips were coated with petroleum gel to reduce the friction between the strips and sides of the box so that the movement of the facing was not affected by the strips.

\section{MODEL NAILS}

Slim rods of brass with a diameter of $0.8 \mathrm{~mm}$ were used to simulate prototype steel nails of $30 \mathrm{~mm}$ diameter. The rods were similar to those used by Sabermahani et al. (2018). The tensile capacity T and modulus of elasticity $\mathrm{E}$ of the brass rods were $115 \mathrm{MPa}$ and $117 \mathrm{GPa}$, respectively. The nails were scaled according to the scaling laws by considering their axial stiffness. In order to simulate the soil-nail interface behavior in the field, the nails were coated with a thin layer of epoxy and sand.

\section{MODEL PREPARATION}

Dry pluviation was used to prepare all the samples. A 20-mm layer of sand was first pluviated as a base layer. The facing sheet then was carefully placed in the arranged location and the other layers ( $20 \mathrm{~mm}$ in height; $\mathrm{D}_{\mathrm{r}}=65 \%$ ) were pluviated. Because the wall facing was not reinforced during pluviation, wooden blocks were placed in front of the wall to prevent movement of the facing.

After completion of pluviation, the wooden blocks were removed in stages and the soil nails were inserted into the soil using a wooden template through the predrilled holes in the facing. The soil nails were pushed into the wall at a vertical spacing of $30 \mathrm{~mm}$ at an inclination of $10^{\circ}$ to the horizontal $\left(\theta=10^{\circ}\right)$ for all models. The vertical spacing of the first and last rows of nails from the bottom and top of the wall was also $20 \mathrm{~mm}$. Horizontal spacing $S_{h}$ of the nails was constant in all rows of a specific model and was varied according to the selected layout ( $L$ and $\alpha$ ) such that $\mathrm{FS}=1.35$ at $50 \mathrm{~g}$.

After preparing the model wall and installing the nails, a plastic bag was placed in front of the wall and was filled with heavy fluid to simulate the soil stress state at rest and at the pre-excavation state. A photograph of the prepared model together with the equipment used is presented in Figure 7. A retaining plate was also used to fill in the gap between the plastic bag and the wall facing.

In each test, centrifugal acceleration was gradually increased in $5 \mathrm{~g}$ increments up to $50 \mathrm{~g}$. After the occurrence of any slight movement in the model at $50 \mathrm{~g}$, the plastic bag was drained gradually by remote control to simulate staged excavation in front of the wall. The centrifugal acceleration was then increased gradually and the behavior and deformation of the wall near failure conditions were observed. Deformation was recorded throughout testing to detect the effect of excavation on the wall.

PIV coupled with close-range photogrammetry as developed by White et al. (2003) was employed to capture images and measure the deformation of the models. A rectangular grid of reference markers consisting of 15 permanent marks was printed on the transparent Plexiglass of the box to allow calibration of the deformations measured by PIV. After defining the reference markers, the GeoPIV code was employed to calculate the deformation of the model in the sequential still images. A few indicative plastic markers were placed near the transparent side of the box inside the model to enable visual recognition of any slip surfaces. These markers were also used to verify the results of the PIV by comparing the visual slip surfaces in the images to slip surfaces obtained by PIV analysis. 
It should be noted that all the measured deformations are presented for the model dimensions. To obtain the corresponding deformations in the field, these measured deformations should be multiplied by the centrifugal acceleration. Because the plastic bag acting as lateral earth pressure system did not perform ideally, it could not prevent the occurrence of slight deformations before simulation of the excavation; thus, all deformations that occurred at $50 \mathrm{~g}$ before the excavation simulation were set to zero.

\section{RESULTS OF CENTRIFUGE TESTS}

Eight centrifuge models were tested. Of these, one model was tested to evaluate the repeatability of the testing method and procedure. The focus has been on finding a relationship between wall performance in terms of crest displacement and layout parameters affecting the performance of the wall. Because, for all model walls, crest displacement was the peak observed displacement of the facing, the results were compared using the components for horizontal, vertical and total crest displacement, denoted by $U(\mathrm{x})$, $U(y)$ and $U(t)$, respectively.

Figure 8 shows the effect of base nail length $L$ on the displacement of the wall crest. Figure 9 shows the effect of the angle of nail tail extension $\alpha$ on displacement at the wall crest. For ease of comparison, displacements were normalized according to the wall height in all graphs.

Figures 8 and 9 reveal that the physical models with different nail layouts at FS $=1.35$ showed very different behaviors. The maximum crest displacement was almost tenfold that of the minimum value in the physical models tested. Therefore, although all the layouts were acceptable in terms of FS, not all models exhibited acceptable performance. It can be concluded that all the layouts proposed to stabilise a wall will not perform similarly and that this should be taken into account in the design of a soil-nailed wall. In addition, parameters $L$ and $\alpha$ showed no meaningful correlation with wall performance and the increase in crest displacement could not be reliably linked to these parameters. It can be concluded that neither $L$ nor $\alpha$ control the performance of the wall independently.

The relationship between the observed displacement components of the wall crest and horizontal spacing of the nails $\left(S_{h}\right)$ is presented in Figure 10. It is evident from Figure 10 that deformation of the wall crest showed a linear relationship with $S_{h}$ and that an increase in $S_{h}$ increased all components of wall crest deformation almost linearly. Therefore, $S_{h}$ could be assumed as an effective parameter for wall deformation. Because each value of $S_{h}$ has been obtained for a specific layout of nails, $D_{n}$ has been used to evaluate the general effect of $S_{h}$, as $D_{n}$ is related to $S_{h}$ as shown in Eq. (1). Figure 11 shows the relationship of the wall deformation components to $D_{n}$.
Figure 11 shows that all components of wall crest deformation were responsive to changes in $D_{n}$ and that any increase in $D_{n}$ caused a decrease in displacement at the crest. It was expected that a further increase in $D_{n}$ would decrease displacement at the crest until it was no longer practical. Therefore, $D_{n}$ was deemed as the most effective parameter studied for the performance of the soil-nailed wall. Observation of the displacements suggests a sensible relationship between $D_{n}$ and wall-crest deformation components. This relationship can be described as:

$U=\alpha\left(D_{n}\right)^{\beta}$.

The influence of $D_{n}$ on wall deformation relates to the mobilized soil mass behind the wall facing that has undergone considerable strain. The rear boundary profiles of the mobilized soil mass after the excavation simulation at $50 \mathrm{~g}$ for all models are shown in Figure 12. The mobilized soil mass profiles obtained by PIV analysis are presented according to $D_{n}$ for better comparison.

Figure 13 shows mobilized soil mass profiles T1- 7-12-3.7 and T7-11-0-8.2 at $D_{n}$ values of 1.31 and 0.83 , respectively. For purposes of comparison, the soil nails were visualized behind the wall. As can be seen in Figure 13, the mobilized soil mass at $D_{n}=1.31$ stretched up to the mid-depth of the wall, mobilizing a large part of the soil behind the wall. While for the model at $D_{n}=0.83$, the mobilized soil mass was limited to the one-third depth of the wall, despite having longer nails than the model with $D_{n}=1.31$.

This trend can be seen in Figure 12 as well. Higher nail densities resulted in larger mobilized soil masses. The effectiveness of the nail density for controlling wall performance can be attributed to the formation of an integrated mass of soil and reinforcing elements. With an increase in $D_{n}$, the more uniform mass of soil and nails resisted displacement and destabilising forces. Integration could have resulted from the soil arching effect that formed between nails with smaller horizontal spaces.

\section{COMPARISON OF FAILURE MECHANISMS AND REPEATABILITY OF TESTS}

Centrifuge modelling has advantages over other methods of modeling, but it can also produce misleading results if the modelling techniques, intricate model preparation and guidelines are not considered. The repeatability of the centrifuge tests must be confirmed for every testing plan. The results of the repeatability evaluation of centrifuge tests are presented below.

The failure mechanism of the soil-nailed wall has been addressed by researchers such as Tufenkjian and Vucetic (2000) and Zhang et al. (2014)). In the current study, however, the failure mechanism was compared to the limit equilibrium results for the slip surface shape and size. Because the onset of failure and its progress is beyond the scope of the current study, 


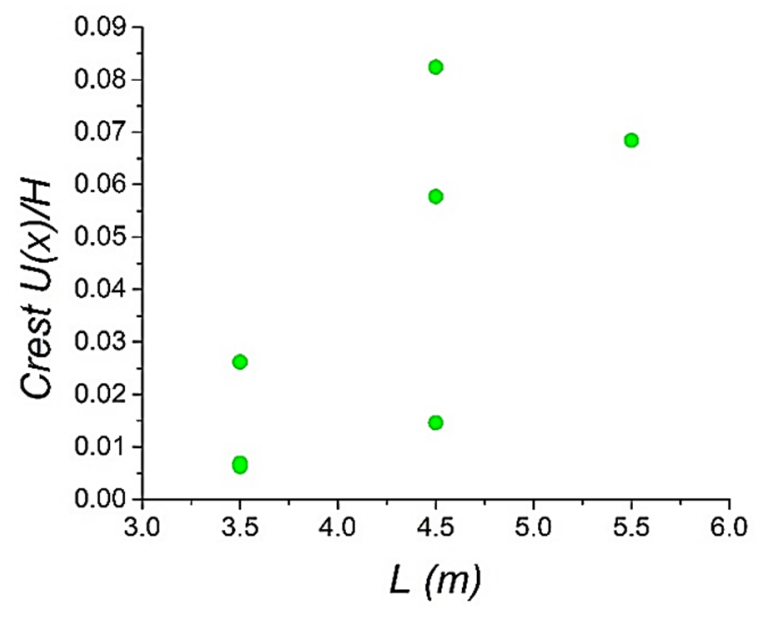

(a)

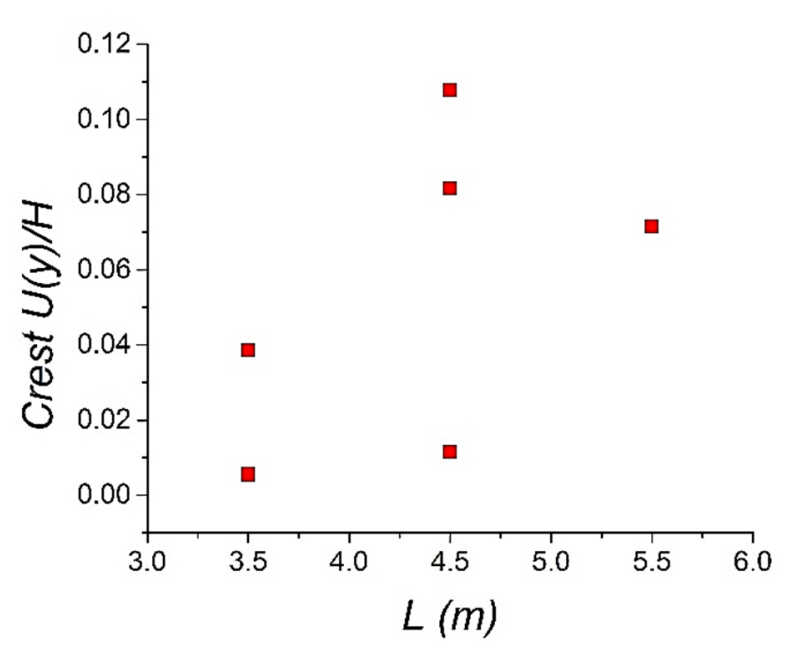

(b)

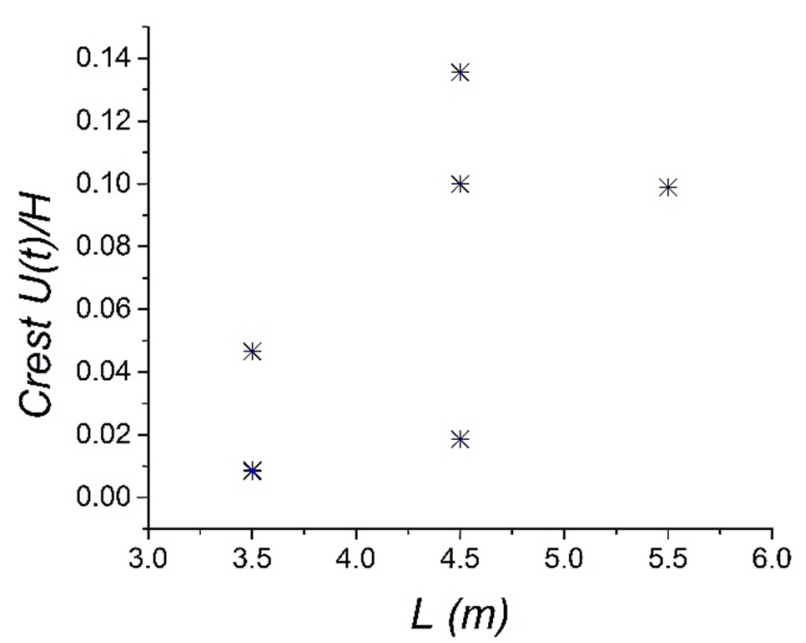

(c)

Fig. 8 Normalized displacement of wall vs. base nail length $L$ : (a) horizontal; (b) vertical; (c) total.

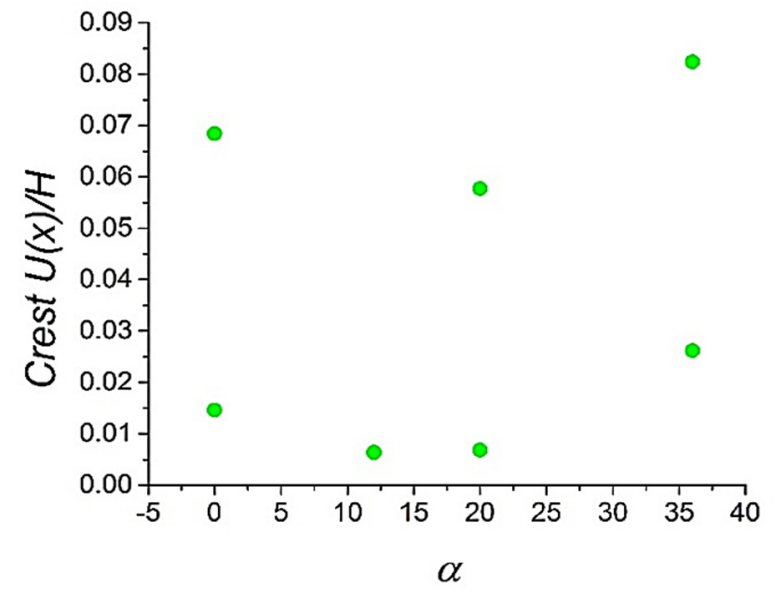

(a)

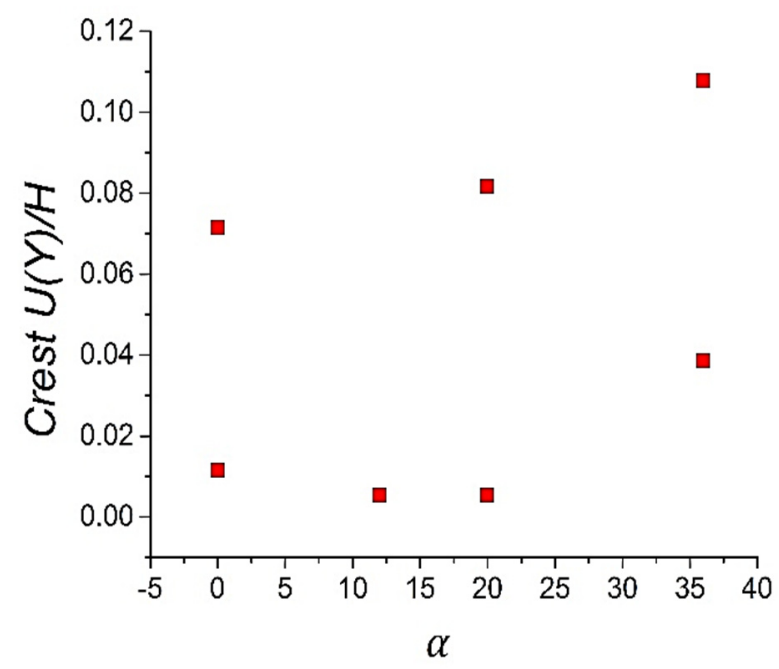

(b)

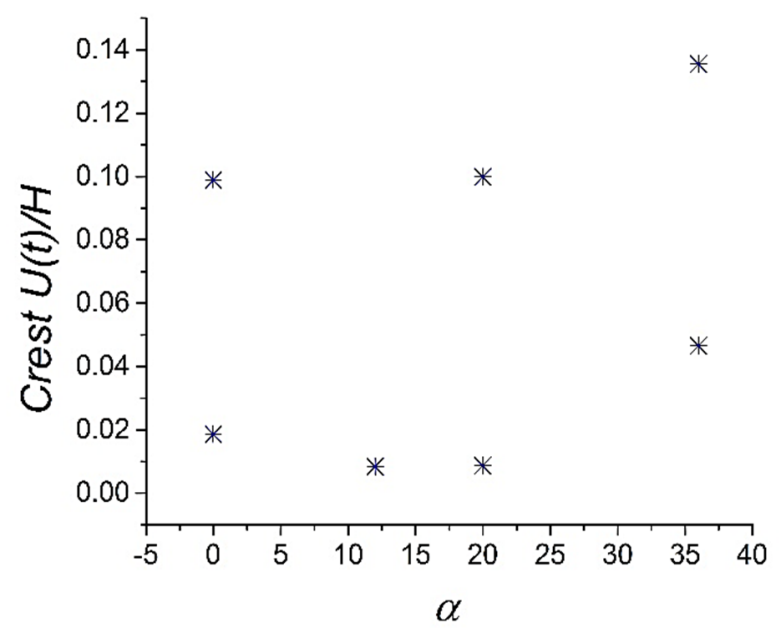

(c)

Fig. 9 Normalized displacement of wall vs. angle of nail tail extension $\alpha$ : (a) horizontal; (b) vertical; (c) total. 


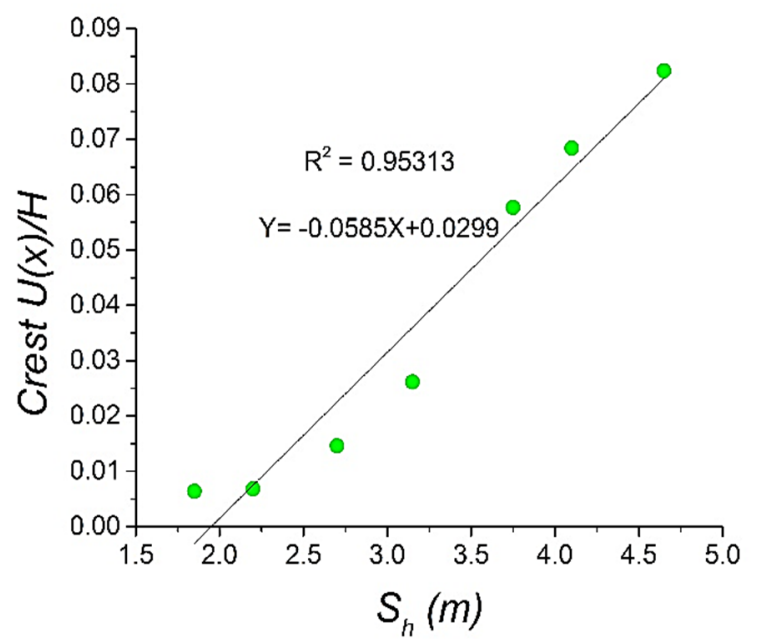

(a)

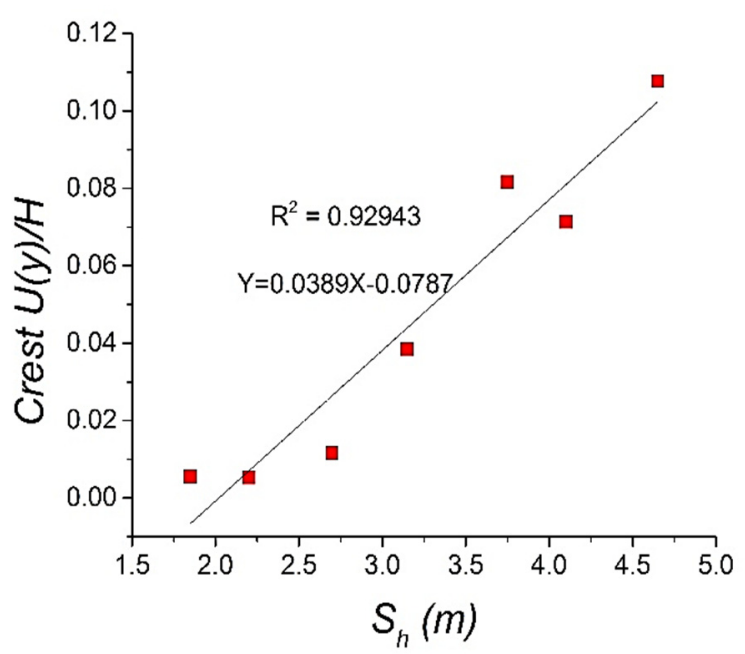

(b)

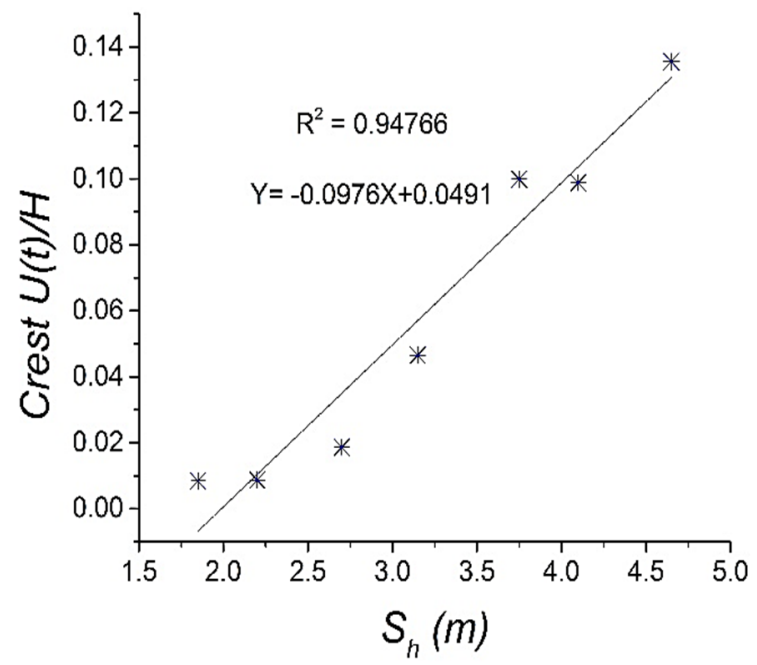

(c)

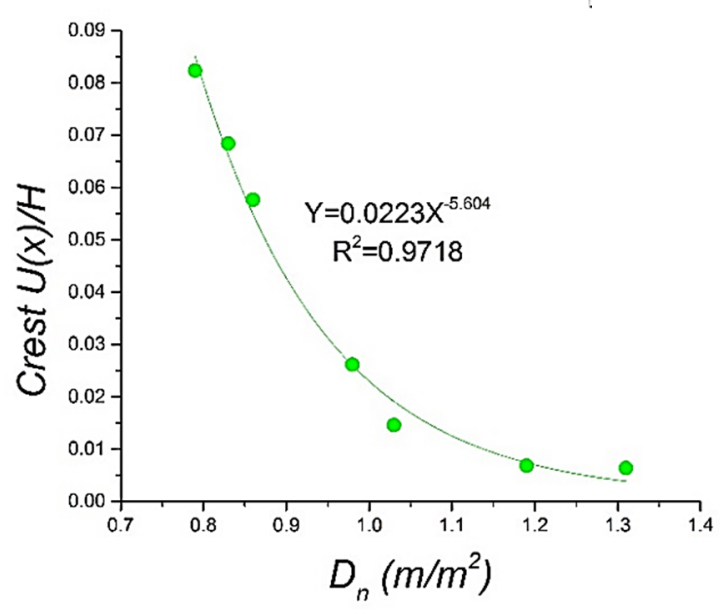

(a)

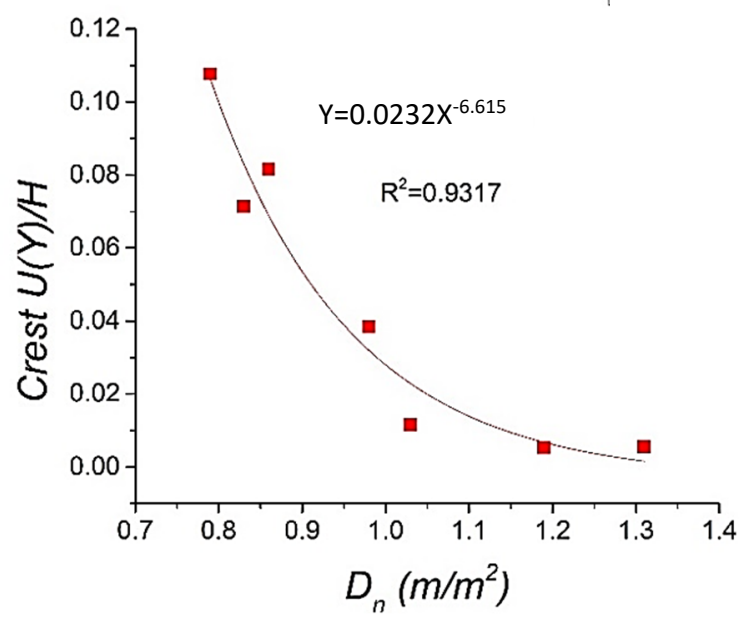

(b)

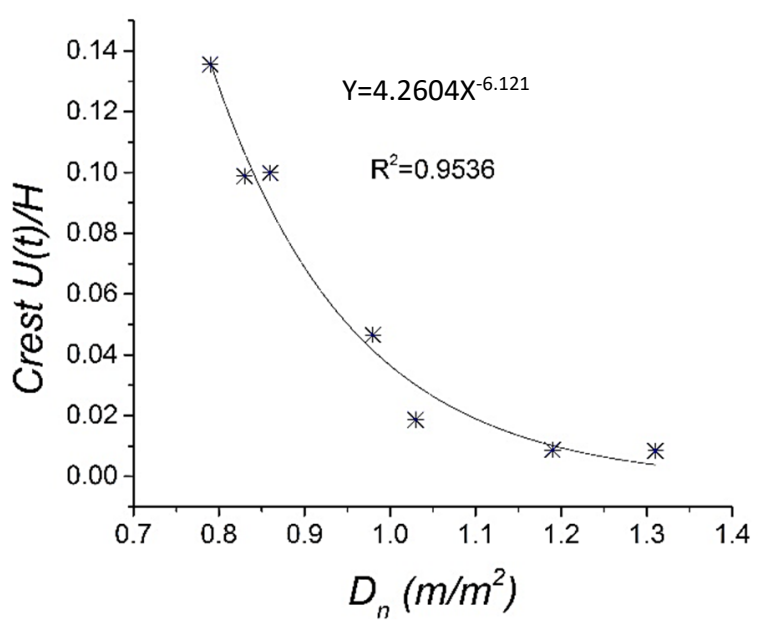

(c)

Fig. 10 Normalized displacement of wall vs. horizontal spacing of nails $S_{h}$ : (a) horizontal; (b) vertical; (c) total.

Fig. 11 Normalized displacement of wall vs. nail density $D_{n}$ : (a) horizontal; (b) vertical; (c) total. 


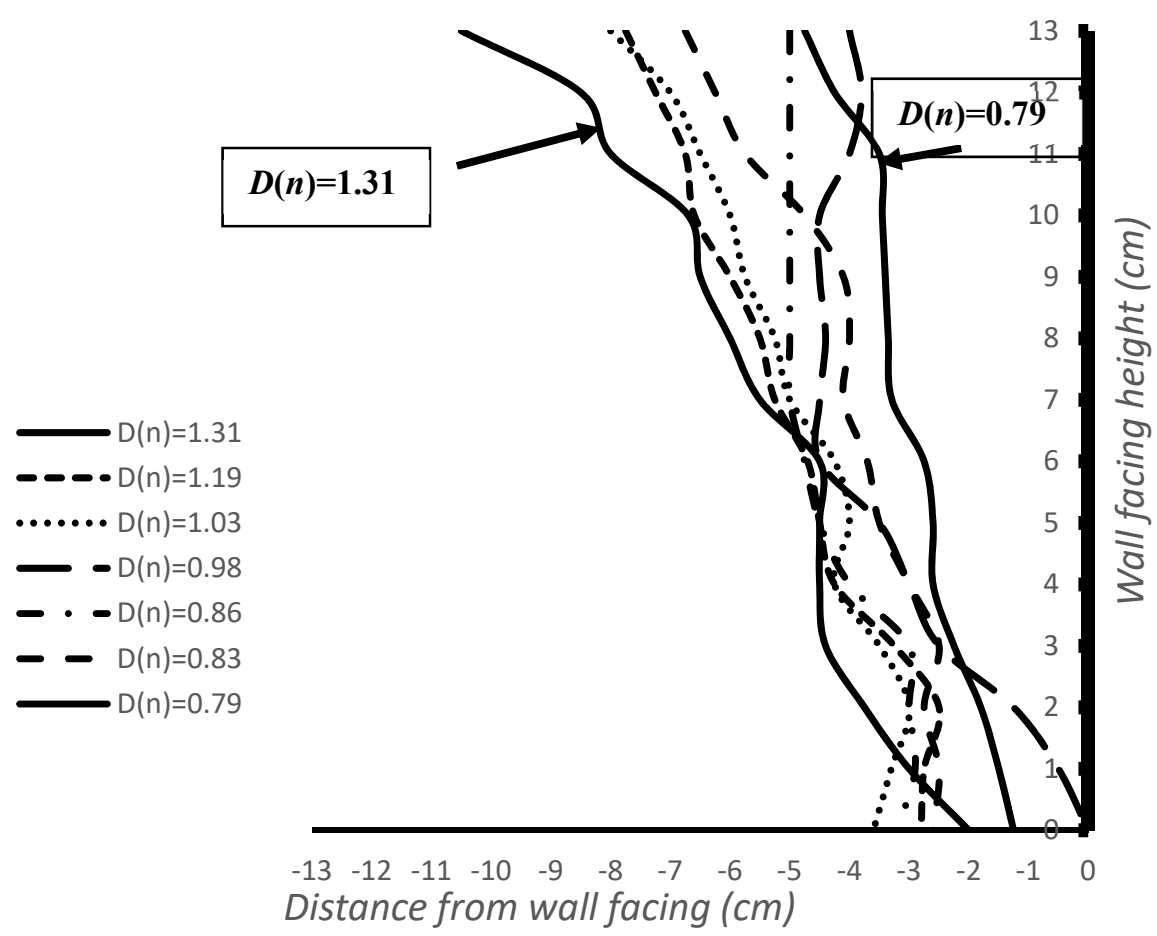

Fig. 12 Mobilized soil mass profile after excavation simulation at $50 \mathrm{~g}$.

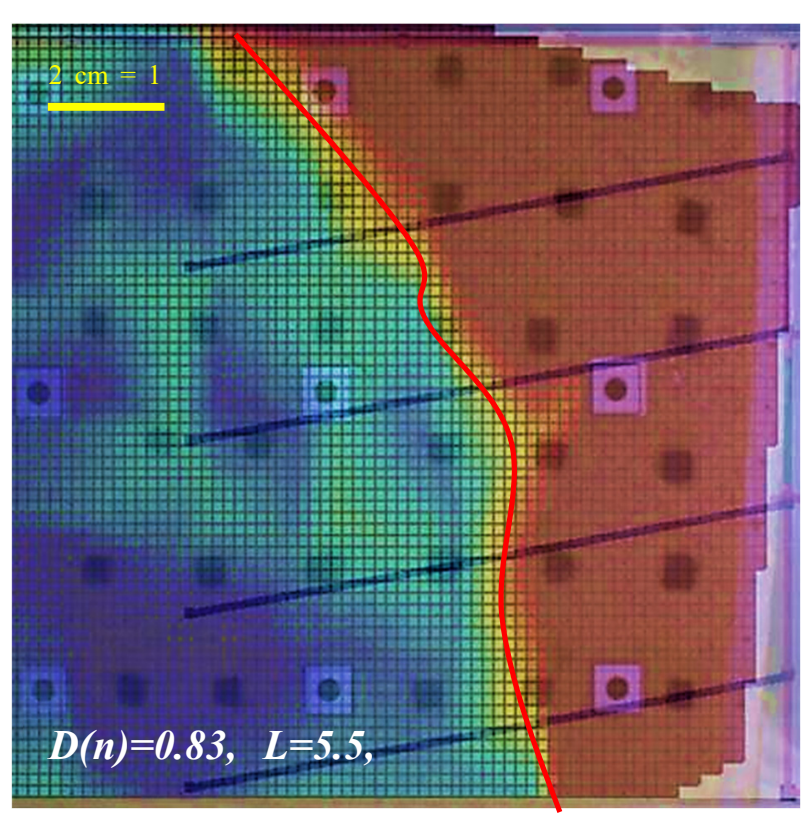

(a)

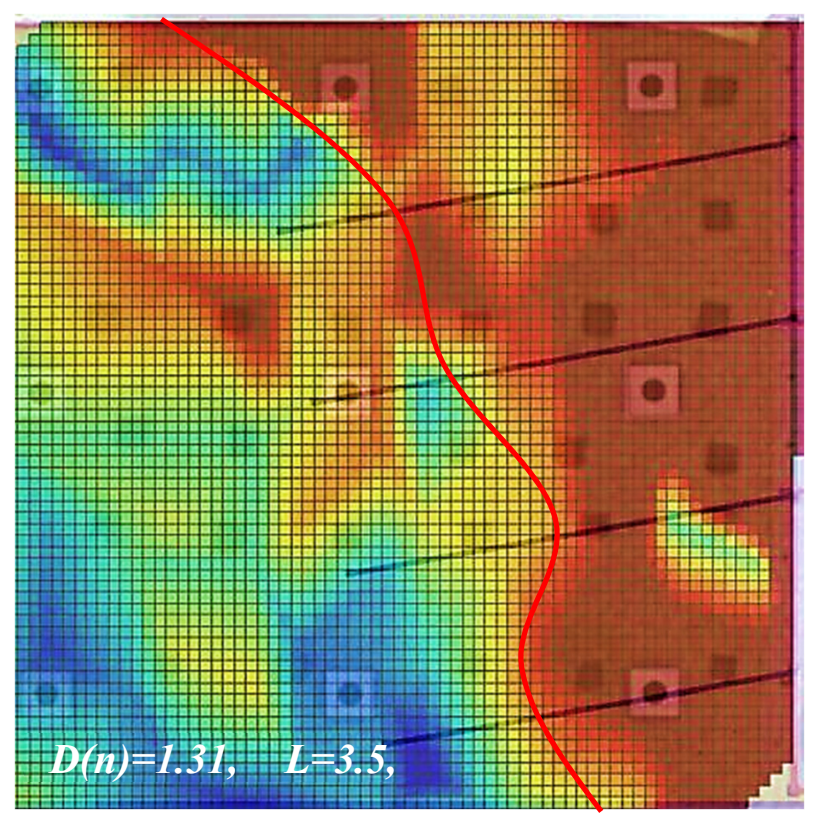

(b)

Fig. 13 Shear Strain contours $(2 \%)$ of the soil behind the wall facing after excavation simulation at $50 \mathrm{~g}$ for: (a) $D_{n}=0.83$; (b) $D_{n}=1.31$.

a preliminary comparison was done to illustrate the similarity. Further investigations on the failure mechanism will be published in a separate technical note.

\section{VERIFICATION OF REPEATABILITY}

Model T8-9-20-7.5 was tested to verify the repeatability of the tests by replicating the results of T5-9-20-7.5. Figure 14 shows the slip surface and strain field for these models. A comparison of the results revealed that the slip surface and deformation 


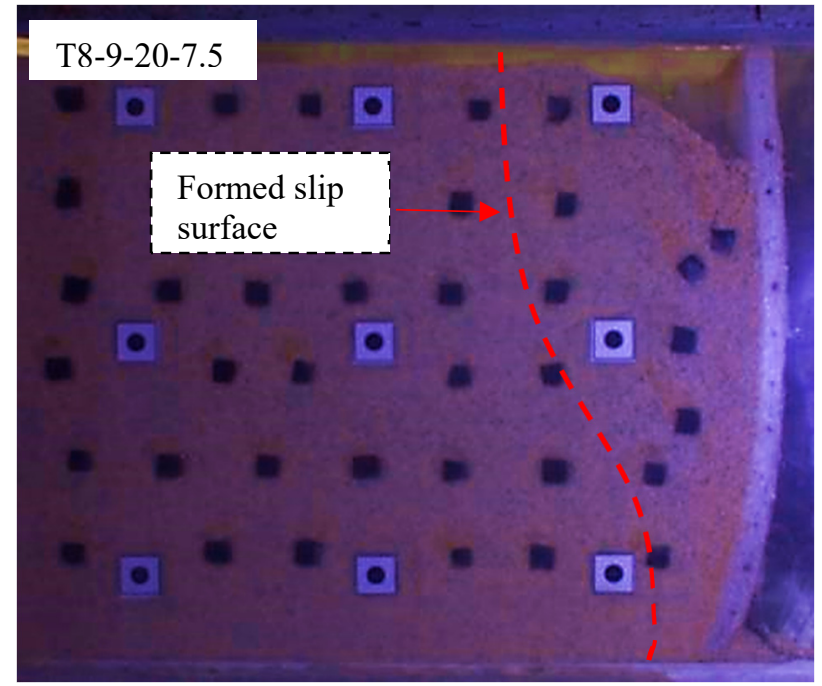

(a)

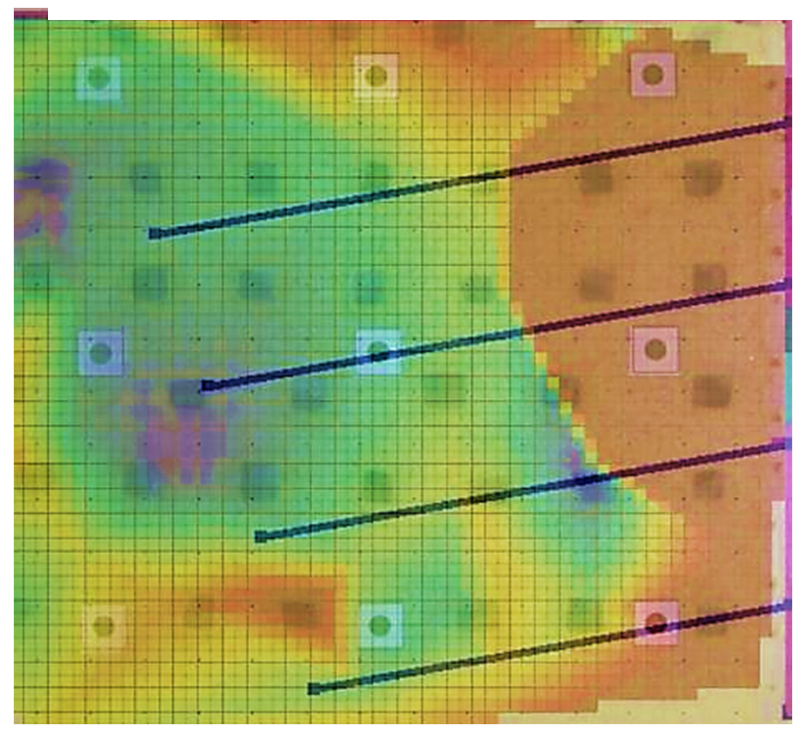

(c)

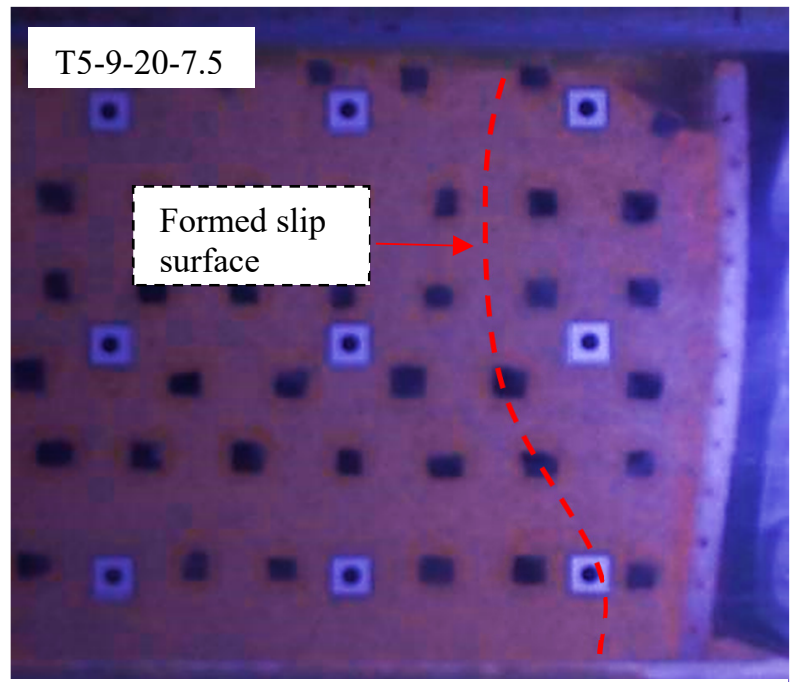

(b)

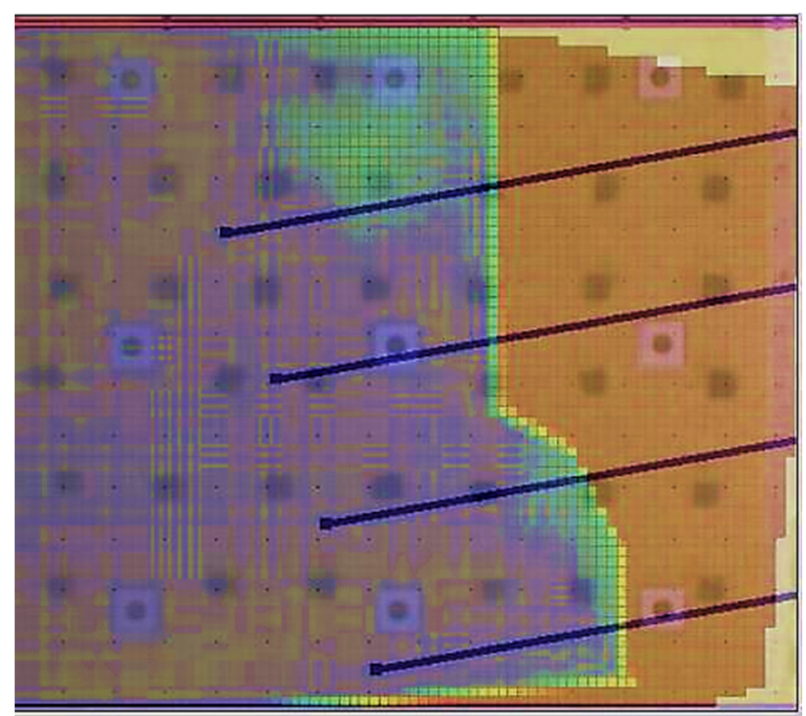

(d)

Fig. 14 Comparison of two models: (a) slip surface of T8-9-20-7.5 model; (b) slip surface of T5-9-20-7.5 model; (c) strain fields at $10 \%$ shear strain for T8-9-20-7.5 model; (d) strain fields at $10 \%$ shear strain for T5-9-20-7.5 model (50 g).

at the crest were acceptably similar, verifying the repeatability of the tests. The slip surfaces for T8- 9- 20-7.5 and T5-9-20-7.5 are depicted in Figures $14 \mathrm{a}$ and $14 \mathrm{~b}$, respectively, in which the similarity of their slip surfaces in terms of shape and distance from the wall facing can be observed. The strain fields obtained by image processing are compared in Figures 14c and 14d.

\section{FAILURE MECHANISMS}

Figure 15 compares the slip surface in model T5-9-20-7.5 at 60g and the slip surface for this model predicted in GeoSlope limit equilibrium analysis. Interestingly, the T5-9-20-7.5 slip surface resembled the predicted slip surface. Although the use of limit equilibrium analysis for a composite system and the expansion of its results to the physical modelling results is not accurate, the slip surfaces were remarkably similar. The safety factor of the GeoSlope model was 0.98 at this g-level, as presented in Table 4 . This is very close to the failure criterion of $\mathrm{FS}=1$ and also demonstrates the reliability of results.

\section{CONCLUSION}

Stabilisation of an excavation by soil-nailing must satisfy two criteria: stability (meeting the minimum factor of safety, FS, as specified by the design codes) and performance (limiting maximum deformation). Limit equilibrium analysis is required in the first step of the design of a soil-nailed wall. After providing the minimum FS, the criteria for performance should be satisfied. In the current study, 


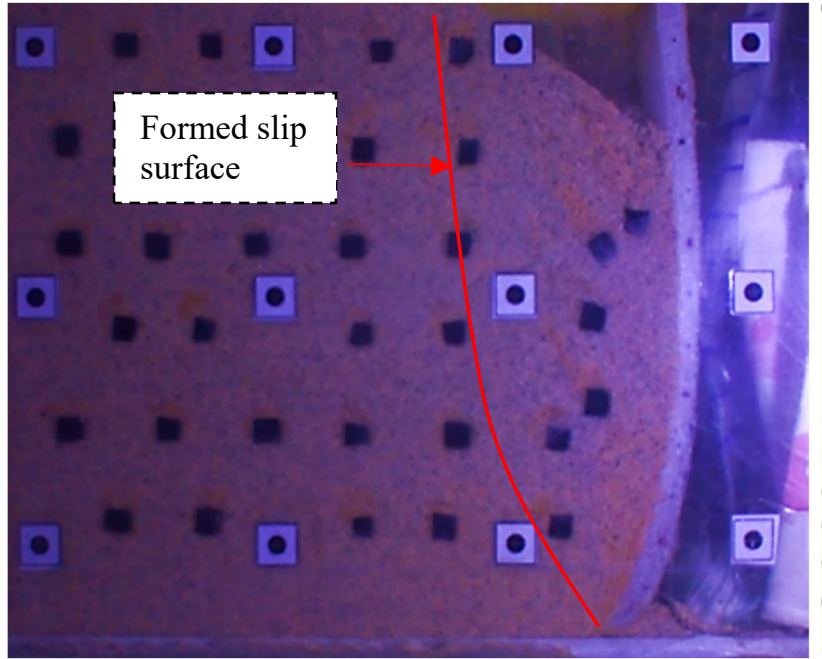

(a)

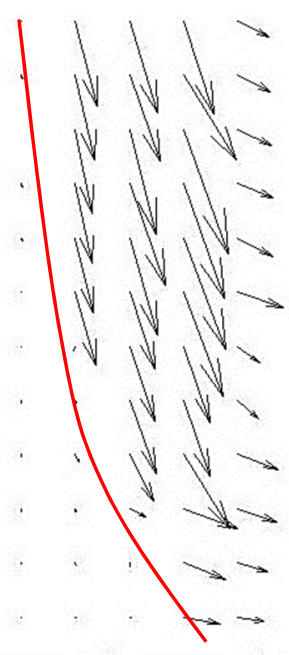

(c)

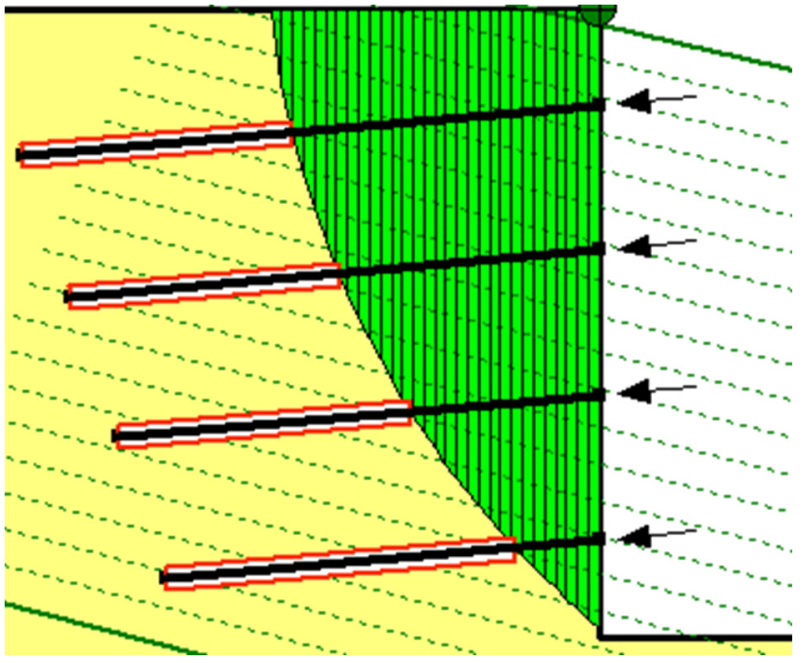

(b)

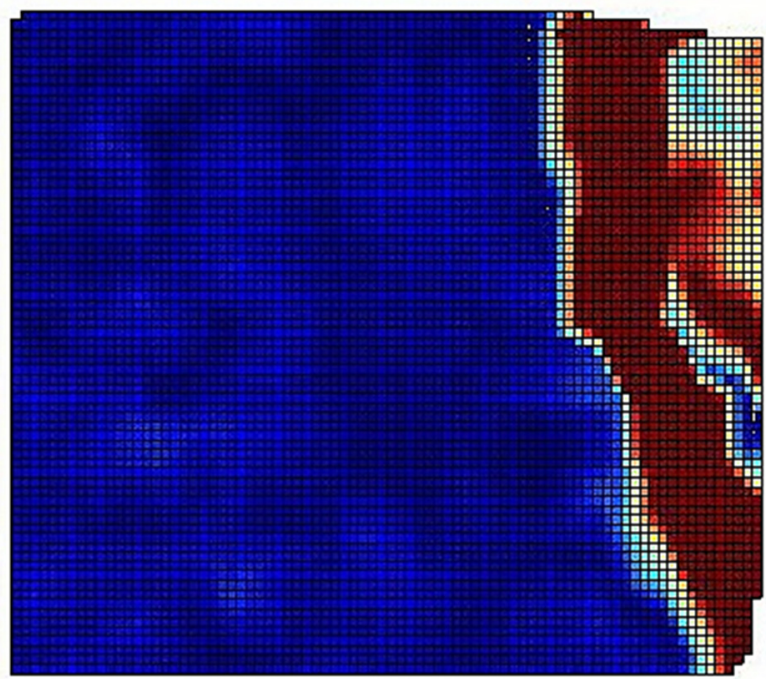

(d)

Fig. 15 Predicted and formed slip surfaces for T5-9-20-7.5 model at $60 \mathrm{~g}$ : (a) centrifuge model which failed at $60 \mathrm{~g}$; (b) limit equilibrium analysis results; (c) PIV results in vector field; (d) PIV results in strain field.

121 layouts were created by combining different values for base nail length $L$ and the angle of nail tail extension $\alpha$ to stabilise a $6.5 \mathrm{~m}$ high vertical trench.

All layouts had a safety factor of 1.35 as recommended by the FHWA for temporary excavations. Seven of these layouts were selected for further investigation using physical modelling in a geotechnical centrifuge to evaluate their performance in terms of crest displacement. The following conclusions were drawn from the results of limit equilibrium analysis and centrifuge testing.

- Limit equilibrium analysis showed that many nail layouts were possible for stabilisation of a trench at $\mathrm{FS}=1.35$, but not all of them would show acceptable performance.

- Increasing $L$ and $\alpha$ caused a decrease in nail density $D_{n}$ until it approached an asymptotic value. The limit equilibrium analysis results indicated that the use of longer nails resulted in higher capacity mobilization of the nails, leading to lower nail density. The use of shorter nails decreased the efficiency of the nails. The use of very short nails was not practical because the recommended value of FS couldn't be obtained. The use of longer nails resulted in a more economical design in terms of FS.

- The results of centrifuge testing revealed that $L$ and $\alpha$ do not have a functional relationship with the wall crest deformation components. However, the horizontal spacing of nails $S_{h}$ and nail density $D_{n}$ strongly influenced deformation of the wall crest. The crest deformation components had a logarithmic relationship with $D_{n}$. Therefore, nail density could be effective for controlling the 
performance of a soil-nailed wall and this should be taken into account when stabilising an excavation using the soil-nailing method.

- The influence of $D_{n}$ on the wall performance can be attributed to the formation of an integrated mass of soil and nails at the higher nail densities. This integrated mass formed because of the soil arching effect between nails with smaller horizontal spacing.

- An empirical relationship was derived between wall deformation components $U(x), U(y)$, and $U(t)$ and nail density as $U=\alpha\left(D_{n}\right)^{\beta}$.

- The slip surface predicted by GeoSlope software and the slip surface that formed in the physical models showed strong similarity in terms of size and shape. Although the comparison of the two was not accurate, the resemblance between the slip surfaces was remarkable.

\section{ACKNOWLEDGEMENTS}

The authors acknowledge the support and assistance of the head of the Geotechnical Engineering Research Center at Iran University of Science and Technology for providing the necessary tools and facilities. The authors also deeply appreciate the support of MR. Faraz Ahimoghadam on physical model construction and his contributions to the testing procedures. The help and support of Prof. David White on PIV analysis is also highly appreciated.

\section{REFERENCES}

Askarinejad, A.: 2006, Parametric study of the behavior of vertical sand trenches by geotechnical centrifuge. $\mathrm{PhD}$. Thesis, Iran University of Science and Technology, Tehran, Iran.

Burland, J., Chapman, T., Skinner, H. and Brown, M.: 2012, ICE Manual of geotechnical engineering Volume 2: Geotechnical design, construction and verification. DOI: $10.1680 /$ moge .57098

Byrne, R.J., Cotton, D., Porterfield, J., Wolschlag, C. and Ueblacker, G.: 1998, Manual for design and construction monitoring of soil nail walls. Report No. FHWA-SA-96-69R, Federal Highway Administration, Washington, DC.

GEO: 2008, Guide to soil nail design and construction (Geoguide 7). Hong Kong, Geotechnical Engineering Office, Civil Engineering and Development.

Ghalehnovi, V.: 2014, Optimization of deep excavations stabilisation systems using artificial neural networks. MSc. Thesis, Iran University of Science and Technology, Tehran, Iran.

Kutter, B.L.: 1992, Dynamic centrifuge modeling of geotechnical structures. Transportation Research Record, No. 1336.

Lazarte, C.A., Robinson, H., Gómez, J.E., Baxter, A., Cadden, A. and Berg, R.: 2015, Soil nail walls. Reference manual geotechnical engineering, circular No. 7, Washington DC.

Milligan, G.W.E. and Tei, K.: 1998, The pull-out resistance of model soil nails. Soils Found., 38, 2, 179-190. DOI: $10.3208 /$ sandf.38.2_179
Morgan, N.: 2002, The influence of variation in effective stress on slopes, serviceability of soil nailed. Ph.D Thesis, University of Dundee.

Petersen, D., Link, R., Zhang, J., Pu, J., Zhang, M. and Qiu, T.: 2001, Model tests by centrifuge of soil nail reinforcements. J. Test. Eval., 29, 4, 315-328. DOI: 10.1520/JTE12261J

Rotte, V.M. and Viswanadham, B.V.S.: 2012, Performance of $2 \mathrm{~V}$ : $1 \mathrm{H}$ slopes with and without soil-nails subjected to seepage: Centrifuge study. GeoCongress, 2012, American Society of Civil Engineers, Reston, VA, 643-652.

Rotte, V.M. and Viswanadham, B.V.S.: 2013, Influence of nail inclination and facing material type on soil-nailed slopes. Proceedings of the Institution of Civil Engineers - Ground Improvement, 166, 2, 86-107. DOI: 10.1680 /grim.11.00026

Sabermahani, M., Ahimoghadam, F. and Ghalehnovi, V.: 2018, Effect of surcharge magnitude on soil-nailed wall behaviour in a geotechnical centrifuge. Int. J. Phys. Model. Geo., 18, 5, 225-239.

DOI: 10.1680/jphmg.16.00022

Sabermahani, M. and Gholaminia, M.: 2017, An study on the effects of nail arrangement on the stability and performance of soil nailed walls. J. Eng. Geol., 11, 2, 1.

Shahnazari, H., Alizadeh, M., Tayefi, S. and Saeedi Javadi, A.: 2019, Three-dimensional centrifuge modeling of soil nail walls. International J. Geotech. Eng., 14, $2,1-$ 8. DOI: $10.1080 / 19386362.2019 .1649887$

Shahraki Ghadimi, A., Ghanbari, A., Sabermahani, M. and Yazdani, M.: 2017, Effect of soil type on nail pull-out resistance. Proceedings of the Institution of Civil Engineers - Ground Improvement, 170, 2, 81-88. DOI: 10.1680 /jgrim. 15.00038

Tufenkjian, M.R. and Vucetic, M.: 2000, Dynamic failure mechanism of soil-nailed excavation models in centrifuge. J. Geotech. Geoenviron. Eng., 126, 3, 227 235. DOI: 10.1061/(ASCE)1090-0241(2000)126:3(227)

Wang, L., Zhang, G. and Zhang, J.-M.: 2010, Nail reinforcement mechanism of cohesive soil slopes under earthquake conditions. Soils Found., 50, 4, 459 469. DOI: $10.3208 /$ sandf.50.459

White, D.J., Take, W.A. and Bolton, M.D.: 2003, Soil deformation measurement using particle image velocimetry (PIV) and photogrammetry. Géotechnique, 53, 7, 619-631. DOI: $10.1680 /$ geot.2003.53.7.619

Zhang, G., Cao, J. and Wang, L.: 2013, Centrifuge model tests of deformation and failure of nailing-reinforced slope under vertical surface loading conditions. Soils Found., 53, 1, 117-129. DOI: $10.1016 / j$.sandf.2012.12.008

Zhang, G., Cao, J. and Wang, L.: 2014, Failure behavior and mechanism of slopes reinforced using soil nail wall under various loading conditions. Soils Found., 54, 6, 1175-1187. DOI: 10.1016/j.sandf.2014.11.011 